\title{
A tradución literaria en Galicia na ditadura (1936-1975), un desafío á lóxica dominante. A primeira tradución de Platero ao galego
}

\author{
Literary translation in Galicia during the dictatorship (1936-1975), \\ a challenge to public authority. The first translation into Galician of Platero
}

\author{
Áurea Fernández Rodríguez \\ Universidade de Vigo \\ Departamento de Tradución e Lingüística \\ aurea@uvigo.es \\ [recibido 16/10/2012, aceptado 02/04/2013]
}

\begin{abstract}
RESUMO
Mediante a análise da primeira tradución ao galego da obra Platero e mais eu, pretendemos amosar que as condicións sociolóxicas, aínda que esenciais, non bastan para dar conta de todo o complexo proceso da tradución. Optamos polo tanto por un modelo flexible capaz de integrar todos os mediadores humanos e non humanos tal e como o entende a teoría do actor-rede. Ademais recuperamos un documento totalmente en vigor na actualidade co que podemos crear un paralelismo entre un contexto hostil pretérito e a actual situación ameazante para unha cultura minoritaria como a galega ante dous fenómenos que se están a vivir no século XXI: a denominada mundialización ou globalización e o nacemento dunha nova forma de ditadura, a dos grandes mercados que dictan as súas normas.
\end{abstract}

PALABRAS CHAVE: ditadura, proceso de tradución minoría, teoría do actor-rede.

FERnÁNDEZ Rodríguez, Á. (2013): “A tradución literaria en Galicia na ditadura (1936-1975), un desafío á lóxica dominante. A primeira tradución de Platero ao galego", Madrygal (Madr.), 16: 31-41.

\section{RESUMEN}

El análisis de la primera traducción al gallego de Platero y yo, nos sirve de base para demostrar que las condiciones sociológicas, aunque esenciales, no bastan para explicar todo el complejo proceso de la traducción. Optamos por lo tanto por un modelo flexible capaz de integrar todos los mediadores, humanos y no humanos, siguiendo la teoría del actor-red. Además recuperamos un documento cuyo mensaje permanece todavía en vigor en la actualidad, pues podemos establecer un paralelismo entre un contexto hostil pretérito con la actual situación amenazante para una cultura minoritaria como la gallega ante dos fenómenos que estamos viviendo en el siglo XXI: la mundialización o globalización y el nacimiento de una nueva forma de dictadura, la de los grandes mercados que dictan sus normas.

PALABRAS ClAVE: dictadura, proceso de traducción, minoría, teoría del actor-red.

Fernández Rodríguez, Á. (2013): “La traducción literaria en Galicia en la dictadura (1936-1975), un desafío a la lógica dominante. La primeira traducción de Platero al gallego", Madrygal (Madr.), 16: 31-41.

\begin{abstract}
The analysis of Platero y yo first translation into Galician during the dictatorship serves as a basis to argue that the sociological conditions, while essential, fail to explain all the difficult work of translation. We therefore opted for a flexible model capable of integrating all human and nonhuman mediators as understood by the Actor Network Theory (ANT). We are also able to go back to a document whose message is still valid today, so that we can establish a parallel between his message in the hostile context of our present history, with the current threat situation for a minority culture such as the Galician there are two separate phenomenas in which we are living in the XXI century: the globalization and the birth of a new reality, the dictatorship of the big markets.

KEY WORDS: dictatorship, the process of translation, minority culture, actor network theory.

FERnÁndez Rodríguez, Á. (2013): "Literary translation in Galicia during the dictatorship (1936-1975), a challenge to public authority. The first translation into Galician of Platero", Madrygal (Madr.), 16: 31-41.
\end{abstract}


SUMARIO: 1. Introdución e estado da cuestión. 2. O proceso de tradución literaria no seu contexto. 3. Estudo de caso: a tradución de Platero e mais eu (1966). 4. Conclusiones. 5. Referencias bibliográficas.

\section{INTRODUCIÓN E ESTADO DA CUESTIÓN}

$\mathrm{Na}$ actualidade a circulación dos textos literarios traducidos depende principalmente do mercado internacional do libro. Trátase dunha transferencia cultural e unha actividade na que interveñen diferentes axentes ou actantes $(\mathrm{Ca}$ llon / Latour 1991) ${ }^{1}$ que se relacionan e rexen o intercambio literario. Os lectores receptores e consumidores son os que máis inflúen na política editorial da literatura porque son os que fixan o valor do libro. Agora ben, na nosa sociedade de consumo actual a demanda móvese condicionada pola propaganda -non hai máis que ver como algúns éxitos resultan de auténticas campañas de mercadotecnia- por iso na práctica son "os chamados "axentes literarios" internacionais e os grandes grupos multinancionais da edición ata os fenómenos relacionados co campo do xornalismo mundial" Lema (2009: 123) os que impoñen a escolla do que se ha de ler. Neste fluxo de textos no que as grandes multinacionais gobernan o mercado do libro, a lóxica dos intercambios culturais e as relacións políticas entre os países permanecen en segundo plano. En cambio, na etapa da ditadura franquista a actividade tradutora e a circulación de textos rexíanse sobre todo pola lóxica das relacións políticas posto que os lectores españois lían, en principio, só o que o que oficialmente o réxime dominante lles permitía. Dito doutro xeito, o mecanismo da censura condicionaba a escolla das obras e os lectores españois non lían o que querían senón o que o goberno franquista necesitaba que lesen.

Mediante o estudo da primeira tradución que se realizou cara ao galego da obra máis universal de Juan Ramón Jiménez (1881-1958), a saber Platero e mais eu, amosaremos que a tradución ten que responder ás necesidades reais dos lectores, último elo na cadea de consumo do libro e a renovar o campo literario de chegada. Esas necesidades ou expectativas son creadas e mesmo manipuladas polas "negociacións" tal e como as entenden os creadores da teoría do actor-rede (actor-network theory, tamén denominada polo acrónimo ANT, Callon / Latour 1991, Latour 1997 e 2006). Mais as relacións entre os diferentes actantes que interactúan segundo unha lóxica de redes no proceso de produción varían segundo os seus propios intereses creados nun determinado contexto social e histórico. Eles son tamén os que buscan asegurar unha recepción favorable no campo literario de chegada.

Esta tradución, que viu a luz nun calendario impreso por gráficas Anmi S. A. o ano 1966, será analizada desde unha dimensión integradora cun triplo obxectivo. Primeiro, trátase de amosar que o complexo proceso da tradución vai máis alá dun simple traslado dun texto de partida a un texto de chegada no que o principal actor é o tradutor, pero non o único. En segundo lugar, preténdese dar a coñecer con maior rigor as relacións dos actantes que participan no proxecto de tradución desde a súa xénese ata a súa recepción, pasando pola súa promoción. Aínda que esenciais, as condicións sociolóxicas non bastan para dar conta de todo o complexo proceso da tradución, polo que optamos por un método que integre diferentes modelos. En terceiro lugar, permítenos establecer un paralelismo entre a súa mensaxe nun contexto político hostil e a actual situación ameazante para calquera mercado de produción pero sobre todo para unha produción restrinxida -como o é o mercado do libro galego- ante dous fenómenos que se están a vivir no século XXI: a mundialización ou globalización e o nacemento dunha nova ditadura, a dos grandes mercados que son os que impoñen o seu criterio no circuito comercial.

Existen diferentes estudos que inclúen traducións realizadas cara ao galego neste período da historia de España. Xa en 1962 Xesús Alonso

\footnotetext{
${ }^{1}$ Para máis información sobre as nocións de "actante", "axente", "actor", "negociación" e "laboratorio" no eido do mercado do libro traducido, e sobre o enfoque teórico integrador no que se pretende encadrar a presente análise, véxase Fernández Rodríguez (2012a: 43-59).
} 
Montero amosara o seu interese pola tradución ao galego en diferentes escritos (Alonso Montero 1962a e 1962b). Máis adiante analizaría de xeito monográfico o tema das traducións dos clásicos latinos e gregos cara ao galego nunha comunicación que presentou no III Congreso Español de Estudios Clásicos (abril 1966). Andrés Pociña tamén lembra as traducións dos clásicos ao galego (1997: 33-43). Noutros medios recóllense algunhas traducións de literatura infantil e xuvenil censuradas nesa etapa para determinar as consecuencias da actividade dos órganos censores e as súas repercusións na formación da xuventude e na cultura española en xeral dos anos 1960 e 1970 (Fernández Rodríguez 2005: 469-484). Aínda que se poden mencionar algúns exemplos máis, o certo é que os clásicos e algún outro autor contemporáneo coñecido eran case os únicos que compoñían o escaso repertorio de traducións no período da ditadura, especialmente nas dúas primeiras décadas (de 1940 ata 1960). Trátase de traducións que aparecían fundamentalmente espalladas en efémeras revistas locais como Posío (Ourense 1945-1946), Alba (A Coruña 1948-Vigo 1950), La Noche. Suplemento del Sábado (1949-1950). Logo, a partir dos anos 1962 volve a resistencia de Grial na que se van introducindo cada vez máis textos en galego de autores estranxeiros. De feito no ano 1970 publicouse xa un número totalmente en galego dedicado a Otero Pedrayo e como non houbo chamada de atención, "desde entón seguiu a ser o galego a única lingua empregada" (Fernández del Riego 2003: 135). No entanto, estas publicacións só quedaban accesibles a grupos moi reducidos de especialistas.

Aínda que non é o noso obxectivo describir o enorme papel que desempeñaron as iniciativas e proxectos da comunidade galega na diáspora, unha historia da tradución galega non pode pasar por alto a actividade tradutora dos ilustrados galegos no exilio. Como xa se apuntou noutra ocasión (Fernández Rodríguez 1995 e 2012b) todas estas traducións feitas fóra ou dentro das fronteiras naturais de Galicia non só deixaron pegadas nas creacións de poetas como Aquilino
Iglesia, Chao Ledo, Cabanillas ou Díaz Castro, senón que constitúen unha arma "combativa" (Casanova 2011), unha forma de expresarse politicamente que empregaban como estratexia para opoñerse ao poder dominante adverso á cultura e lingua galegas. Porén a maioría da poboación galega quedaba fóra deste "combate" porque non tiña medios para acceder ás publicacións nin ás correntes culturais a favor da lingua que se difundían de maneira precaria por distintos medios.

\section{O PROCESO DA TRADUCIÓN LITERA- RIA NO SEU CONTEXTO}

Os actantes que interveñen na tradución de Platero e mais eu sinten a necesidade de importar textos diferentes aos que ofrece a vía oficial, pero teñen que competir nunha loita desigual cos actantes dependentes non só do poder político da época senón tamén do poder económico, xa que o almanaque ou calendario de 1966, no que se pode ler a tradución ao galego titulada Platero e mais eu, era un produto cultural que se imprimiu para ofrecelo como agasallo e non con ánimo de lucro nin sequera para ser destinado ao mercado. A sociedade na que se desenvolve a tradución resulta determinante posto que, definida polas súas macroestruturas (clases sociais, ideoloxías...) ou polas competencias particulares dos seus actores (aprendizaxe cultural), esa sociedade desempeña o papel de mecanismo regulador (Callon / Latour 1991: 33). A actividade tradutora ao estar intimamente ligada aos intereses políticos e á sociedade na que se inscribe é susceptible de converterse nun éxito ou nun fracaso. Coidamos que para dar conta do éxito ou do fracaso dunha tradución (condicionado polo contexto social no que se produce) cómpre analizar o seu proceso de produción ${ }^{2}$ (principio de simetría de Latour 1997) no que participan tanto actantes humanos como non humanos. Os datos sobre a distribución e as estratexias que tiveron que adoptar os iniciadores do proceso desta tradución ao galego non se poden explicar e avaliar mediante unha única perspectiva como podería ser a da teoría de Pierre Bourdieu (1992,

\footnotetext{
${ }^{2}$ Callon / Latour (1991) miran cara ao proceso de innovación científica e técnica, mais pódese suxerir que a tradución dun texto compórtase como a produción de calquera outro produto
} 
1998) porque non contempla actantes non humanos e datos empíricos que nos proporcionou Xesús Alonso Montero, o responsable da selección dos capítulos de Platero que se traduciron do castelán ao galego por primeira vez e que se debullarán no apartado 3 dedicado á análise do proceso de tradución da obra.

No eido das ciencias sociais ou da socioloxía da ciencia desenvolveuse en Francia, paralelamente aos traballos de Bourdieu e da súa escola, unha corrente de pensamento representada por MadeleineAkich, Michel Callon e Bruno Latour, creadores da teoría da socioloxía máis coñecida como teoría do actor-rede (ANT, Actor Network Theory). Nesta teoría nocións como transformación, compromiso e cadea de tradución (Callon / Latour 1991) son conceptos fundamentais. A ANT non se opon á filosofía de Bourdieu senón que ofrece un complemento válido para explicar a complexidade do proceso de tradución tanto se se trata de analizar todo un corpus ${ }^{3}$ como unha simple obra ou unha parte dela, como é o caso de Platero. Esta visión proporciona "a methodological and theorical framework" (Buzelin 2005: 202) capaz de suplir as carencias dos métodos tradicionais que se están a empregar na actualidade. O concepto de "negociación" tal e como o entenden Callon e Latour, que inclúe todo o que se discute no "laboratorio", resulta determinante. Cun enfoque integrador poderemos botar luz sobre os motivos da escolla da obra e responder a diferentes interrogantes: ¿por que esa obra e non outra?, é dicir ¿que criterios primaron á hora de seleccionala?, ¿en que momento e como emerxeu o proxecto?, ¿como interactúan e como negocian os actantes (Callon / Latour 1991)?, ¿como se mobilizaron?, ¿que papel desempeña o tradutor no proxecto?, ¿o tradutor participou nas negociacións ou limítase a actuar como mediador entre dúas culturas?, ¿cal era a súa intención? Nun contexto social e político no que o idioma galego non estaba permitido, ¿cales son os medios materiais que facilitaron que a tradución chegase ao público lector?,¿cal foi a súa recepción posto que non dispoñemos de datos oficiais?, etc.

Un reducido grupo de intelectuais galegos -Ángel Gómez Camarón, Epifanio Ramos de Castro e Xesús Alonso Montero- adoitaban reunirse nunha taberna situada onde se atopa actualmente o hotel Méndez Núñez, rúa da Raíña de Lugo ${ }^{4}$. Nunha desas reunións un tanto clandestinas naceu o proxecto de tradución ao galego da obra máis representativa de Juan Ramón Jiménez, Platero e mais eu. Un dos protagonistas, o empresario Ángel Gómez Camarón, mestre socialista, posuía un pequeno obradoiro denominado Cartonaxes Anmi S. A., no que se elaboraban bandexas, pratos, caixas... que se utilizaban para o envoltorio de empanadas, doces e traxes. Nesta ocasión Ángel Gómez Camarón desexaba imprimir un texto literario para felicitar aos seus clientes. O catedrático de francés de instituto e autor de varios libros como La pronunciación francesa (Lugo: Celta, 1963), Epifanio Ramos de Castro, propuxo a tradución de Platero para conmemorar o décimo aniversario da concesión do premio Nobel ao clásico español. Xesús Alonso Montero, que non estaba totalmente entusiasmado coa escolla, foi o encargado da selección dos capítulos ${ }^{5}$ que lles foron asignados a cada tradutora e a cada tradutor que se implicaron neste traballo colectivo de tradución. Os que asinaron a tradución eran nomes xa moi coñecidos da cultura galega vinculados co nacionalismo ou co galeguismo moi comprometidos coa súa terra e que sentían a necesidade de transformar a situación do país. Deseguido ofrécese a relación dos autores e autoras tal e como asinaron: Ramón Otero Pedrayo, Sebastián M. Risco, Celso Emilio Ferreiro, Jesús Alonso Montero, José L. Méndez Ferrín,

\footnotetext{
${ }^{3}$ Como podería ser a tradución de calquera outra obra nesta ou noutra etapa. Para un mapa completo das traducións desde o galego e cara ao galego na etapa da democracia, desde 1980, véxase a Biblioteca Galega de Tradución (BITRAGA: http://www.bibliotraducion.uvigo.es/).

${ }^{4}$ Agradecemos a D. Xesús Alonso Montero a información que nos achegou sobre o proxecto.

5 Tamén foi o encargado da escolma de efemérides e eventos que aparecen nos distintos meses do calendario dese ano 1966. O máis nutrido é o mes de outubro no que se sinalan 15 celebracións entre as que destacamos: nacemento do Semanario lugués “A monteira” (5 de outubro de 1889), Curros Enríquez é coroado na Coruña (21 de outubro de 1904), desterro de A. de la Peña (29 de outubro de 1813), nace a revista Nós (30 de outubro de 1920), publicación de Longa noite de pedra de Celso Emilio Ferreiro (15 de outubro de 1962), etc.
} 
Camilo G. Suárez Llanos, Ánxel Fole, Albino Núñez Domínguez, Arcadio López Casanova, María Xosé Queizán, Antía Cal, José Ramón Fernández Oxea, Xohana Torres e Ricardo Carballo Calero.

A empresa luguesa Cartonaxes Anmi, moi comprometida coa cultura galega - xa acordara subvencionar o premio de teatro "Castelao" o 20 de marzo de 1965-, conseguiu así editar no seu almanaque para o ano 1966 a tradución Platero e mais eu que incluía unha tamén nutrida lista de debuxantes aos que se lles encomendaron as ilustracións: Vázquez Díaz, Isaac Díaz Pardo, Mercedes Ruibal, Agustín Pérez Bellas, Virxilio Fernández, Julio Maside, Manuel Colmeiro, Grandío, Blás Lourés, Manuel del Río, Laxeiro, Manuel Pesqueira, Xohan Ledo e Ánxel Gómez. $\mathrm{O}$ feito de aceptar a encarga xa supón por parte dos tradutores e ilustradores unha escolla, unha opción ideolóxica diferente á establecida e unha proba de resistencia que implicaba certos riscos porque baixo o réxime ditatorial a tradución debía estar ao servizo do Estado e só se importaban obras traducidas ao castelán. A presenza nos repertorios de tradución das demais linguas, catalán, galego e vasco estaba minguada porque, aínda que non había ningún decreto que as prohibise, non se permitía o seu emprego fóra do ámbito familiar. A consigna que lanzaba a política totalitaria franquista "Un Estado, una lengua" ou fórmulas como "habla en cristiano, no ladres", "habla el idioma del imperio" para impoñer o castelán como única lingua válida en todo o Estado creaba un ambiente inestable e destrutivo para a cultura en xeral e para o equilibrio social dunha sociedade bilingüe.

Malia a represión ían aparecendo algúns textos traducidos que xurdían principalmente da iniciativa de intelectuais defensores da liberdade. Nun primeiro momento os textos espallados en revistas locais dirixíanse sobre todo a outros intelectuais. Mais pouco a pouco foron sentindo a necesidade de empregar a tradución cara ás linguas minorizadas para sensibilizar ao pobo da riqueza da súa cultura marxinada polas institucións e organismos ao servizo do Estado.

\section{ESTUDO DE CASO: A TRADUCIÓN DE PLATERO E MAIS EU (1966)}

Neste contexto no que o idioma galego só era de uso oral, os intelectuais galegos tiñan que servirse de subterfuxios, buscar estratexias para burlar a censura e conseguir que chegasen aos fogares galegos textos escritos no seu idioma materno. Velaí un dos motivos polos que a tradución de Platero se divulga nun aparentemente inocente almanaque. A empresa pretende agasallar aos seus clientes: "Cartonaxes Anmi quere que os seus amigos e clientes camiñen este ano d'acabalo do burro mais fermoso e humano que se coñece" (Cartonaxes Anmi 1966). As persoas que viñan mercar a Lugo aínda que se expresaban en galego non adoitaban ler textos no seu idioma materno. As escasas ocasións que se lles presentaban eran outros calendarios anuais como O Gaiteiro de Lugo que desde 1936 se editaba totalmente en galego por iniciativa de Xosé Filgueira Valverde, entón catedrático no Instituto de Lugo e colaborador nas sucesivas edicións ata 1957 , ano do centenario ${ }^{6}$. O número de 1963 foi o último imprentado por Gerardo Castro antes de que se vendese a cabeceira a $L a$ Región de Ourense.

O éxito do almanaque coa tradución de Platero quedou garantido se temos en conta o número de exemplares que se distribuíron. Segundo Xesús Alonso Montero o público que se beneficiou do texto foi "duns centos", é dicir, unha cantidade razoable para a época. O éxito debe ser medido sobre todo, non polo número de lectores (que tamén), senón sobre todo polo valor simbólico que representaba o proxecto no contexto no que se proxectou. A experiencia tivo continuidade xa que Cartonaxes Anmi editou outro calendario para o ano 1968 dedicado a lembrar algúns galegos ilustres "que deixaron impreso o fondo calco da súa laboura" (Cartonaxes Anmi 1968) 7 como Pablo Iglesias, Noriega Varela, Castelao, Valle Inclán, etc.

Entre os factores garantes da boa acollida da tradución hai que destacar de forma especial o prestixio da obra e do autor homenaxeado

${ }^{6}$ A súa creación data do 1857 por Manuel Soto Freire do que foi continuación Artes gráficas do impresor Gerardo Castro e máis tarde o seu fillo, de igual nome ata 1963. 
ademais da canle empregada para a difusión e a popularización do texto traducido. J. R. Jiménez non militou nunca en ningún partido político, mais polo seu elevado sentido da liberdade, a Guerra Civil fíxoo tomar unha postura decidida a favor do Goberno de España elixido democraticamente polo pobo español o 16 de febreiro de 1936. O alzamento militar do 18 de xullo de 1936 simbolizaba para J. R. Jiménez, como para os demais liberais, un atentado contra as liberdades populares polo que tivo que abandonar o país. Na introdución do almanaque titulada "Juan Ramón Jiménez, visto por nos" Ánxel Fole, nomeado membro numerario da Real Academia Galega en 1963, fai a presentación do prestixioso autor andaluz e da súa obra ademais de traducir o capítulo. 43 ("Amistade").

O 25 de outubro de 1956 a Academia sueca outorgoulle o Premio Nobel de Literatura polo que era unha excelente ocasión para celebrar o décimo aniversario da súa concesión. J. R. Jiménez era non só un "vello amigo de Galicia e dos seus poetas" (Anmi 1966), un gran admirador dos autores galegos como Rosalía de Castro (1837-1885) e Curros Enríquez (1851-1908), senón tamén tradutor dos seus poemas.

No capítulo 17 de Platero -titulado no almanaque galego "O neno parvo", traducido por
Xesús Alonso Montero ${ }^{9}$ e ilustrado por Agustín Pérez Bellas para acompañar ao mes de abrilocupa un lugar privilexiado o poeta galego $\mathrm{Cu}-$ rros Enríquez: "Curros, pai mais que poeta, que, cando se quedou sin o seu neno, preguntáballe por íl á volvoreta galega. Volvoreta d'aliñas douradas...". As lecturas de Curros deberon influír moi cedo no poeta andaluz, posiblemente xa no 1896, xa que no curso sobre "El Modernismo" (1953) ${ }^{10}$ que impartiu na Universidade de Puerto Rico explica que as súas lecturas eran Bécquer, Rosalía de Castro, Curros Enríquez, en galego os dous cuxos poemas traducía e publicaba nun periódico de Huelva segundo se manifesta no vespertino La Noche. Suplemento del sábado (nº 10 18/12/1949).

$\mathrm{Na}$ parte central do calendario e despois do mes de xuño no que aparece a tradución do capítulo 29, "Idilio de abril", de Camilo G. Suárez Llanos, atópase a tradución que J. R. Jiménez realizou cara ao castelán dos poemas dos dous grandes clásicos galegos. De Rosalía de Castro lemos: a última parte de "Pra Habana" e "Negra sombra", poemas que evocan o drama da emigración galega e que se atopan incluídos en Follas novas, unha das obras fundamentais da autora de Padrón. De Curros Enríquez, inclúese a tradución de “¡Ai!” (Aires da miña terra).

\begin{tabular}{|c|c|}
\hline Curros Enríquez & Trad. de J. R. Jiménez \\
\hline $\begin{array}{l}\text { ¡Ai! } \\
\text { ¿Como foi?... - eu topábame fóra } \\
\text { cando as negras vixigas lle deron; } \\
\text { polo aramio súa nai avisoume } \\
\quad \text { i eu vime correndo. }\end{array}$ & $\begin{array}{l}\text { ¿Ay! } \\
\text { ¿Cómo fue? Me encontraba yo fuera } \\
\text { y mi niño cayó muy enfermo. } \\
\text { Me llamó con un parte su madre } \\
\quad \text { y vine corriendo }\end{array}$ \\
\hline
\end{tabular}

\footnotetext{
${ }^{7}$ O proxecto inicial consistía en presentar trinta biografías, pero foi necesario reducir o número por problemas de colaboracións, segundo sinala na súa presentación A. Gómez Camarón, un mestre comprometido cuxo desexo era divulgar algún aspecto da cultura galega e "invitar a outros comerciantes e industriais amigos que fan a propaganda por iste medio de calendario anual, a que basen en temas ou asuntos que teñan un sentido mais positivo que o que normalmente se ven facendo" (Cartonaxes Anmi, 1968).

${ }^{8}$ Para unha análise dos aspectos lingüísticos da tradución deste, véxase o artigo de Palacio Sánchez (1997: 94-97).

${ }^{9}$ O 17 de maio de 1963 Xesús Alonso Montero publicou o artigo "Juan Ramón Jiménez, traductor de Curros Enríquez" no vespertino La Noche, onde destaca a influencia de Curros sobre Juan Ramón Jiménez moi sensibilizado cos nenos mortos, enfermos e abandonados.

${ }^{10}$ Os apuntes foron publicados pola editorial Aguilar no ano 1962 baixo o título El modernismo: notas de un curso (1953), logo máis tarde apareceu unha nova edición de Jorge Urrutia en Visor (1999).
} 
¡Coitadiño! Sintindo os meus pasos revolveu cara a min os seus ollos. Non me viu... e chorou...jai! xa os tiña ceguiños de todo.

Non me acordo que tempo me estiven sobre o berce de dor debruzado; sólo sei que me erguín co meu neno sin vida nos brazos...

Bolboreta de aliñas douradas que te pousas no berce baleiro, pois por el me preguntas, xa sabes que foi do meu neno.
¡Pobrecillo! Sintiendo mis pasos,

hacia mi revolvía sus ojos.

No me vio, y lloró. ¡Los tenía Ya ciegos del todo!

No me acuerdo del tiempo que estuve en la cuna de dolor doblado, sólo sé que me erguí con mi niño sin vida, en los brazos.

Mariposa de alillas doradas que a la cuna vacía has venido, si por él me preguntas, ya sabes que fue de mi niño.
En “¡Ai!”, J. R. Jiménez quedará marcado polo símbolo da "Bolboreta de aliñas douradas" recorrente nas páxinas de Platero. A bolboreta, de rico simbolismo e gran transcendencia, aparece en varios capítulos da obra. Representa a transformación da vida, a súa fugacidade, a natureza fráxil da vida humana, pero tamén a inmortalidade do espírito. No capítulo 2 "Mariposas blancas" a bolboreta simboliza a espiritualidade dun xeito leve. Pouco a pouco vaise manifestando con todo o seu valor (a espiritualidade transcende en eternidade) nunha interesante graduación: primeiro, no capítulo 131, baixo a visión das bolboretas, unha branca e outra negra, presaxio de morte; despois, no capítulo 132, traducido por Xohana Torres, aparece como unha bolboreta de tres cores cando Platero morre. Finalmente as "vagas mariposas blancas" (capítulo 133) que se unen ás flores en conxunción de eternidade, resólvense nunha definitiva bolboreta branca que "arrevoaba teimosamente, o mesmo que unha ialma de lilio en lilio" (cap. 135, tradución de R. Carballo Calero).

Outro aspecto interesante que non podemos deixar de comentar é o da estrutura da obra que o grupo da rúa Raíña coñecía ben. As vivencias de Platero discorren nun período cronolóxico que abarca un ano: comezan na primavera, á que se alude no capítulo 8 , e rematan na mesma estación, no capítulo 135 . Pois ben, a tradución respecta o ciclo completo do ano, dende xaneiro ata decembro, como todo calendario; pero o mes de xaneiro comeza co capítulo 1 ("Platero") que traduce Ramón Otero Pedrayo e o ano péchase no mes de decembro con dous capítulos, o 132 que traduciu Xohana Torres e o 135 traducido por Carballo Calero baixo o título de "malencolía"; ilustrados polos debuxos de Manuel Pesqueira e de Xohan Ledo, respectivamente. $\mathrm{O}$ calendario abre cunha ilustración dun burro de Saturno Lois e pecha con outra de Castelao sacada do libro Cousas que completa un fragmento titulado "Cousa". Se temos en conta as "normas preliminares" de Gideon Toury $(1980,1995,2004)$, aquelas que están relacionadas coa "política tradutora", é dicir, con aspectos que afectan á elección do texto que se quere traducir, teremos que engadir que a obra formaba parte do programa nas escolas na España de Franco, polo tanto ben coñecida polo público español en xeral e polo galego en particular na súa versión orixinal.

A cada colaborador foille asignado un capítulo de Platero, un para cada mes do ano, agás para os meses de outubro e decembro. Así ao carón do mes de outubro atópase o capítulo 79, "Alegría", traducido por $\mathrm{M}^{\mathrm{a}}$ Xosé Queizán e dous capítulos máis: o capítulo 102, "susto" en versión galega de Antía Cal de Beiras e "A ialba", capítulo 114 na versión do poeta da Terra Cha, Manuel María. Como xa se dixo, o mes de decembro pecha o calendario con dous capítulos, o 132, "A morte" e o 135, "Malencolía". Esta estrutura permanece moi ligada á presenza da bolboreta. Símbolo da alma xa dende a antigüidade clásica, a bolboreta simboliza tamén riqueza espiritual e sangue como sinal de dor humana.

En defintiva, a escolla destes capítulos é representativa do conxunto da obra e ao mesmo tempo responde ás intencións xerais e particulares do proxecto. Nese ano 1966, trinta anos despois do comezo da cruenta Guerra Civil e dez despois de que lle fose concedido o Nobel a J. R. Jiménez, a iniciativa en Galicia ten moito mérito. En primeiro lugar porque se trata dunha 
tradución ao galego que, aínda que non recolle a totalidade da obra, ten a orixinalidade de ser a primeira que se fixo de Platero. En segundo lugar, a tradución dos distintos capítulos coidadosamente escollidos non é mais que unha estratexia para elidir aquilo que non se podía explicitar nun período de despotismo político: o pensamento crítico e o sentir duns tradutores comprometidos coa súa lingua, coa súa cultura, coa súa sociedade e coa súa terra. $O$ traballo é unha achega á cultura galega sometida naquela época a duras probas posto que todas as publicacións tiñan que pasar polo filtro e os controis dos mecanismos da censura. A censura actuaba severa ou brandamente segundo a notoriedade política do escritor, a súa visión historiográfica da historia e a cultura e, evidentemente, segundo a súa notoriedade literaria. Era particularmente dura cos libros escritos nas linguas minorizadas como o catalán, o éuscaro e o galego. Ademais de ser unha homenaxe a J. R. Jiménez, a tradución cara ao galego difundida nun almanaque era un desafío ao poder dominante, unha forma de dignificar a lingua e a cultura galegas, pero tamén unha chamada á sociedade que debía tomar conciencia da riqueza cultural e do seu compromiso co país. O traballo pretende implicar á comunidade para conseguir o cambio de actitude fronte á cultura e á lingua galegas estigmatizadas, maltratadas historicamente, expulsadas de todos os ámbitos, tanto do administrativo como do educativo ou relixioso.

Xa en territorio de democracia a versión galega completa de Platero viu a luz en formato libro no ano 1990 da man de Manuel Beiras (Eubensei) patrocinada pola Subdirección do Libro da Consellería de Cultura da Xunta de Galicia. Esta versión cunha función didáctica e normalizadora, logo ben diferente á primeira que aparece no almanaque de Anmi S. A., encetou un dos períodos máis ricos en tradución cara ao galego do século XX. A proba de que se trata dunha contribución á normalización e ao enriquecemento da lingua galega queda confirmada polo feito de que cada capítulo vai seguido dunha lista de termos co seu significado, pero tamén queda patente nunha carta que D. Benito Varela
Jácome dirixe a D. Manuel Beiras despois de ler a tradución e que se inclúe no libro. Salientamos a seguinte pasaxe: "A túa versión, ademais de artellar con acerto as equivalencias dos dous sistemas lingüísticos, significa unha recreación vizosa do galego; arrequece a nosa lingua con novas connotacións e imaxes...".

A carta, con data do 11 de xaneiro de 1983, dá fe igualmente de que a publicación tivo lugar bastante máis tarde que o proceso de tradución. Este feito chama a atención posto que corre o risco de producir un desfase entre a intención do tradutor e a función final do texto traducido. Pois a mensaxe dun texto (traducido ou orixinal) varía en función da correspondencia que pode manter coas forzas externas, as que se desenvolven no campo do poder ou do campo social no seu conxunto. Ao modificaren as circunstancias históricas en que aparecen os textos perden o seu contido e as expectativas non se cumprirían, pero esta cuestión sería xa obxecto doutro estudo.

Os resultados destas traducións cara ao galego dan conta dos movementos sociais, das correntes ideolóxicas en Galicia e mesmo ofrecen resposta a outros feitos posteriores: ¿que representaron estes proxectos para a democratización de Galicia, para a normalización da lingua e da cultura galegas? Aínda que con recursos diferentes, estes tradutores - defensores da cultura e da lingua galegas certo, pero sobre todo auténticos actores- atoparon aquí unha forma de expresión axeitada co momento histórico que lles tocou vivir. $\mathrm{O}$ almanaque era naquela época o soporte que mellor podía canalizar as intencións do proxecto de tradución ata os sectores máis populares que ían ter diante dos ollos as páxinas colgadas na parede dalgún cuarto da súa casa durante todo o ano. Era un proxecto innovador e chamaba a atención do público polo seu contido, pois habitualmente os calendarios estaban feitos "a base de señoras estupendas (como diría Álvaro de la Iglesia)" como salienta A. Gómez Camarón na presentación do almanaque do 1968 xa mencionado e editado tamén por Cartonaxes Anmi.

${ }^{11}$ Para uns datos cuantitativos e cualitativos sobre o fenómeno da tradución en Galicia nese período de 1980 a 2010 véxase Fernández Rodríguez / Luna Alonso / Galanes Santos / Montero Küpper (2012). 


\section{CONCLUSIÓNS}

Concordamos con Carlos Lema en que a tradución é "o meirande mecanismo de importación e exportación (...) tanto se nos referimos a textos coma ao repertorio de formas literarias" (2009: 122). No contexto da ditadura, a tradución de Platero en 1966 representaba sobre todo unha actividade política, cultural e tamén propagandística que se creou baixo un esquema de cooperación e de loita colectiva contra a restrición de liberdades políticas que minguaban a creación literaria. A medida que se ía recuperando a vida política fíxose cada vez menos necesario disfrazar a actividade literaria de acción cultural $^{12}$ para centrarse máis na dinamización da lingua nos anos da etapa da transición. Co rescate desta tradución pretendemos interpretar e reinterpretar para evitar repetir modelos obsoletos ou para adoptar modelos innovadores alí onde os haxa. Como afirma Meschonnic a práctica se non se reflexiona sobre ela e unha teoría da tradución que non implique a reflexión dunha práctica sería simplemente nonpensamento (Meschonnic 2009: 45). Nos fluxos literarios a tradución non é só un instrumento de comunicación e información entre linguas e culturas senón que é unha práctica ideolóxica que realiza o tradutor que actúa como axente activo e comprometido co bo uso do produto (ética), e non como un mero pasador de sentido (Meschonnic 2007). De feito a lectora ou o lector galegos dos anos 1960 (tampouco os dos anos 1980 ou 1990) non precisaban da tradución de Platero ao galego posto que o podían ler en castelán ${ }^{13}$ e xa o facían na escola. No entanto o tradutor non é o único que participa neste proceso, xa que outros actantes interactúan nunha cadea de tradución que se vai construíndo na controversia e "qui lie des énoncés et des enjeux a priori incommensurables et sans communes mesures" (Callon / Latour, 1991: 32). A reflexión sobre esas interaccións, relacións e fenómenos, aínda que sexan pretéritos, permiten comprender a forma de relacionarnos no mundo actual cada vez máis dado a retos e desigualdades do tipo: literaturas dominantes / literaturas dominadas, literaturas autónomas / heterónomas, literaturas non reivindicativas / literaturas combativas, lingua imperio / lingua minorizada, centro / periferia, imperialismo / colonialismo, nacionalismo / mundialización, etc.

\section{REFERENCIAS BIBLIOGRÁFICAS}

Alonso Montero, Xesús (1962a): "Las primeras traducciones del catalán al gallego", La Noche (18/8/1962).

(1962b): “Aquilino Iglesia Alvariño, traductor al gallego de textos latinos y griegos”, Estudios Clásicos VI/36, pp. 582-583.

(1968): "Textos griegos y latinos traducidos al gallego. Bibliografía”, en Actas del III Congreso Español de Estudios Clásicos (Madrid, 28 marzo - 1 abril 1966). Madrid: Sociedad Española de Estudios clásicos, vol. 2, pp. 9-17.

(1996): Ensaios breves de literatura e politica. Vigo: Editorial Nigra.

Alonso Montero, Xesús / Epifanio Ramos De Castro (1966): Cen anos de literatura galega: catálogo da exposición bibliográfica celebrada no Círculo de las Artes de Lugo (9-19 decembro 1963). Lugo: Círculo de las Artes.

Bitraga: Biblioteca da Tradución Galega (http://www.bibliotraducion.uvigo.es/).

Bourdieu, Pierre (1998): Les règles de l'art. Genèse et structure du champ littéraire. París: Éditions du Seuil.

${ }^{12}$ En referencia á poesía escribe Carlos Casares anos máis tarde: "Estes e outros poetas [Méndez Ferrín e A. Pexegueiro], sin renunciaren a unha concepción política da poesía, saben que o valor dun poema non depende somentes da súa carga comunicativa nin da súa intencionalidade política, senón que sobre todo depende da súa organización estética" (Casares 1978: 509).

${ }^{13}$ Sobre a tradución español-galego-español véxase Fernández Rodríguez (2008). 
Callon, Michel / Bruno Latour (1991): La science telle qu'elle se fait. Anthologie de la sociologie des scinces de langue anglaise. París: Éditions La Découverte.

Cartonaxes Anmi (impr.) (1968): Calendario 1968. Lugo: Anmi. Impreso por talleres gráficos de Anmi.

Casanova, Pascale (2011): "La guerre de l'ancienneté", en Pascale Casanova, Des littératures combatives. L'internationale des nationalismes littéraires. Paris: Éditions raisons d'agir, pp. 9-32.

Casares Mouriño, Carlos (1978): "Literatura e movemento teatral”, en José Antonio Durán (dir. e coord.), Galicia. Realidade económica e conflito social. A Coruña: Ed. Banco de Bilbao (imprime La Voz de Galicia), pp. 498-515.

Fernández Del Riego, Francisco (2003): Camiño andando. Vigo: Galaxia.

FERnÁNDEZ RodRíGUEZ, Áurea (1995): "O papel da traducción no sistema lingüístico e literario nacional: o ámbito galego", Grial 33, pp. 541-554.

(2005): “Tradución e manipulación na última etapa franquista. O caso das obras xuvenísinfantís", en V. Ruzicka Kenfel / C. Vázquez García / L. Lorenzo García (eds.), Mundos en conflicto: representación de ideologías, enfrentamientos sociales y guerras de la literatura infantily juvenil. III Congreso Internacional de ANILIJ (Universidade de Vigo, Centro Cultural Caixanova de Vigo, 3-5 decembro 2003). Vigo: Universidade, pp. 469-484.

(2008): "La traducción literaria en el siglo XXI español-gallego-español", en Asumpta Camps / Lew Zybatow (eds.), Traducción e interculturalidad. Frankfurt am Main: Peter Lang, vol. 9, pp. 125-140.

(2011): "La traducción en Galicia y la industria editorial (1980-2008)", en Enric Gallén / Francisco Lafarga / Luis Pegenaute (eds.), Traducción y autotraducción en las literaturas ibéricas. Bern, Berlin, Bruxelles, Frankfurt am Main, New York, Oxford, Wien: Peter Lang (Series: Relaciones literarias en el Ámbito Hispánico 2), pp. 93-109.

- (2012a): "Un modelo metodológico multidisciplinar. Nuevas herramientas, nuevos enfoques", en Áurea Fernández Rodríguez / Ana Luna Alonso / Iolanda Galanes Santos / Silvia Küpper (eds.), Traducción de una cultura emergente. La literatura gallega contemporánea en el exterior. Bern, Berlin, Bruxelles, Frankfurt am Main, New York, Oxford, Wien: Peter Lang (Series: Relaciones literarias en el Ámbito Hispánico 7), pp. 43-59.

(2012b): "La traducción y la actividad editorial de los exiliados gallegos en Hispanoamérica”, en Francisco Lafarga / Luis Pegenaute (eds.), Lengua, cultura y política en la historia de la traducción en Hispanoamérica. Vigo: Academia del Hispanismo, vol. 2, pp. 61-70.

Fernández Rodríguez, Áurea / Ana Luna Alonso / Iolanda Galanes Santos / Silvia Küpper (2012): Traducción de una cultura emergente. La literatura gallega contemporánea en el exterior. Bern, Berlin, Bruxelles, Frankfurt am Main, New York, Oxford, Wien: Peter Lang (Series: Relaciones literarias en el Ámbito Hispánico 7).

JiMÉnEZ, Juan Ramón (1966): Platero e mais eu (ed. por talleres gráficos Anmi S. A., en Calendario 1966). Lugo: Anmi [tradución ao galego por diferentes tradutores e tradutoras].

(1985): Platero y yo. Madrid: Anaya.

(1990): Platero e mais eu (versión galega de Manuel Beiras (Eubensei), patrocinada pola Subdirección do Libro da Consellería de Cultura da Xunta de Galicia). A Coruña: Ediciós do Castro.

(1999): El Modernismo: apuntes de curso (1953) (ed. Jorge Urrutia). Madrid: Visor.

Latour, Bruno (1997): “On Actor-Network Theory. A few Clarifications”, en http://cibersociologia. com/web/index2.php?option=com_content\&do _pdf=1\&id=18 (consulta 7/7/2012).

(2006): Ré-assembler le social. Introduction à l'acteur-réseau. Paris: La découverte [1 ${ }^{\mathrm{a}}$ edición en inglés 2005]. 
Lema, Carlos (2009): "Importación e exportación de textos literarios. Unha crítica á noción de literatura mundial como paradigma", Grial XLVII/182, pp. 120-135.

Meschonnic, Henri (2009): Ética y politica del traducir (trad. Hugo Savino; original: Éthique et politique du traduire, 2007). Buenos Aires: Leviatán.

Palacio Sánchez, Antón (1997): “Ánxel Fole, traductor”, en Xesús Alonso Montero (ed.), Ánxel Fole: Día das Letras Galegas 1997. Santiago de Compostela: Universidad, pp. 89-103.

PociÑA, Andrés (1997): “Traduccións das linguas clásicas ó galego”, Viceversa. Revista Galega e Tradución 3, pp. 33-43.

TOURY, Gideon (1980): In search of a theory of translation. Tel Aviv: Porter Institute for Poetics and Semiotics.

(1995): Descriptive translation studies and beyond. Amsterdam/Philadelphia: John Benjamins Publishing Company.

(2004): Estudios descriptivos de traducción y más allá : metodología de la investigación en estudios de traducción. Madrid: Cátedra. 